\title{
Video Capsule Endoscopy in Small-bowel Malignancy: A Multicenter Belgian Study
}

\author{
D. Urbain ${ }^{1}$, D. De Looze ${ }^{2}$, I. Demedts ${ }^{3}$, E. Louis ${ }^{4}$, O. Dewit ${ }^{5}$, E. Macken ${ }^{6}$, A. Van Gossum ${ }^{7}$ \\ ${ }^{1}$ Hepato-Gastroenterology Unit, AZ VUB, Brussels, Belgium \\ ${ }^{2}$ Gastroenterology Unit, UZ Gent, Belgium \\ ${ }^{3}$ Gastroenterology Unit, Gasthuisberg, KUL, Leuven, Belgium \\ ${ }^{4}$ Gastroenterology Unit, CHU de Liège, Belgium \\ ${ }^{5}$ Gastroenterology Unit, Cliniques Universitaires Saint-Luc, UCL, Brussels, Belgium \\ ${ }^{6}$ Gastroenterology Unit, UZ Antwerpen, Belgium \\ ${ }^{7}$ Gastroenterology Unit, Clinique Erasme, ULB, Brussels, Belgium
}

Background and Study Aims: Early diagnosis of small-bowel tumors is crucial for therapy. Video capsule endoscopy has improved the diagnosis of small-bowel diseases, but data concerning the role of this technique in detecting small-bowel malignancy are scarce. The aim of this paper was to review all capsule endoscopy findings at Belgian hospitals, in order to evaluate the diagnostic yield of capsule endoscopy in the field of smallbowel malignancy.

Patients and Methods: For this retrospective study, the seven Belgian academic hospitals where the device was being used were asked to review the findings obtained by means of video capsule endoscopy, and to collect information about the cases of small-bowel malignancy.

Results: In total, 443 capsule endoscopies were performed up to November 2004, and 11 malignant small-bowel processes were detected (2.5\%). The most frequent indications for performing capsule endoscopy in those 11 cases were intestinal bleeding of undefined origin or iron-deficiency anemia. The mean number of diagnostic procedures performed before capsule endoscopy was 3.6. The capsule endoscopy results had a diagnostic yield of $1.6 \%$ after classical work-up. In $55 \%$ of these cases, capsule endoscopy findings had an influence on therapy.

Conclusions: Tumors of the small bowel remain a rare condition. Video capsule endoscopy is able to detect tumors undiagnosed by classical procedures in about $1.6 \%$ of cases and has an impact on the therapy in $55 \%$ of the tumor cases.

\section{Introduction}

Diagnosis of small-bowel disease is difficult due to the partial inaccessibility of this organ to endoscopy. In particular, vascular lesions escape the traditional work-up using small-bowel series. Video capsule endoscopy was devised to improve the diagnosis of small-bowel diseases. The M2A video capsule endoscope (Given Imaging, Yoqneam, Israel), a wireless capsule $27 \mathrm{~mm} \times 11 \mathrm{~mm}$ in size, has been available for clinical purposes for 3 years.

A range of indications became apparent with time, especially in the field of bleeding of undefined etiology. For this indication, capsule endoscopy provides an added diagnostic yield superior to that of push enteroscopy, i.e., of 50\%-67\% versus 25\%-30\% [1,2]. Different authors have also demonstrated the superiority of capsule endoscopy compared with small-bowel radiography [3] or entero-computed tomography (CT) [4]. Other indications for capsule endoscopy are Crohn's disease, nonsteroidal anti-inflammatory drug (NSAID)-induced small-bowel damage, celiac disease and chronic diarrhea. Data on the ability of capsule endoscopy to detect small-bowel tumors are, however, scarce, and the value of capsule endoscopy for detecting tumors is still being debated $[5,6]$.

\section{Patients and Methods}

The results of capsule endoscopy procedures up to November 2004 were retrospectively reviewed in the seven Belgian academic hospitals where capsule endoscopy is carried out. Only malignant small-bowel tumors were taken into account. The following information was gathered from the patient files: age, sex, indication for performing capsule endoscopy, diagnostic procedures (endoscopies, small-bowel radiographs, CT scan) 
undergone before performance of capsule endoscopy, description and estimated location of the tumor, final diagnosis, and impact of capsule endoscopy findings on the management of the patient. The final diagnosis was obtained by histological examination of biopsy specimens or of surgical resection pieces.

For all capsule endoscopy procedures, the M2A video capsule endoscope was used. At each center, patients fasted for 8-10 hours before the procedure. At two centers, polyethylene glycol was used the day before the examination. No medications were used during the capsule endoscopy. Reading times at the centers varied between 40 and 90 minutes.

\section{Results}

In total, 443 capsule endoscopies were performed at the seven centers, and from these 443 procedures, 11 malignant processes of the small bowel were identified (2.5\%). These were found in six women and five men, whose mean age was 63.4 years $(55-76)$.

The indications for performing capsule endoscopy in these patients had been:

- intestinal bleeding of unidentified origin and iron-deficiency anemia, $\mathrm{n}=7$;

- protein-losing enteropathy (PLE) and malabsorption, $\mathrm{n}=2$;

- episode of intestinal occlusion with spontaneous resolution, $\mathrm{n}=1$; and

- abdominal lymph nodes detected on CT scan, $\mathrm{n}=1$.

The details for these patients (age, sex, indication, histological findings, location of malignancy, endoscopic appearance, and type of treatment) are presented in Table 1.

Table 1. Details of the patients with small-bowel malignancy

\begin{tabular}{|c|c|c|c|c|c|}
\hline $\begin{array}{l}\text { Patient no., } \\
\text { sex, age }\end{array}$ & Indication & Histology & $\begin{array}{l}\text { Location of } \\
\text { malignancy }\end{array}$ & Appearance & Treatment applied \\
\hline $1, \mathrm{~F}, 57$ & $\begin{array}{l}\text { Iron-deficiency } \\
\text { anemia }\end{array}$ & Adenocarcinoma & $\begin{array}{l}\text { Proximal } \\
\text { jejunum }\end{array}$ & Bleeding tumor & Surgery \\
\hline $2, M, 67$ & $\begin{array}{l}\text { Episode of } \\
\text { intestinal } \\
\text { occlusion }\end{array}$ & Multifocal carcinoid tumor & $\begin{array}{l}\text { Multiple, } \\
\text { in the small- } \\
\text { bowel }\end{array}$ & $\begin{array}{l}\text { Nodular and } \\
\text { polypoid tumors }\end{array}$ & Surgery \\
\hline $3, \mathrm{M}, 76$ & $\begin{array}{l}\text { Iron-deficiency } \\
\text { anemia }\end{array}$ & Adenocarcinoma & $\begin{array}{l}\text { Distal } \\
\text { jejunum }\end{array}$ & Stenosing mass & $\begin{array}{l}\text { Surgery and } \\
\text { chemotherapy }\end{array}$ \\
\hline $4, M, 55$ & $\begin{array}{l}\text { Lymph nodes on } \\
\text { CTscan }\end{array}$ & $\begin{array}{l}\text { Low grade T-cell } \\
\text { lymphoma (diagnosis by } \\
\text { lymph node biopsy) }\end{array}$ & Jejunoileal & Erosions, ulcers & Chemotherapy \\
\hline $5, F, 60$ & $\begin{array}{l}\text { Malabsorption } \\
\text { Protein-losing } \\
\text { enteropathy }\end{array}$ & $\begin{array}{l}\text { T-cell lymphoma (Figure } \\
\text { 1) (biopsy obtained during } \\
\text { push enteroscopy) }\end{array}$ & Jejunoileal & $\begin{array}{l}\text { Deep ulcers } \\
\text { Bleeding }\end{array}$ & Chemotherapy \\
\hline $6, M, 64$ & $\begin{array}{l}\text { Unidentified } \\
\text { intestinal bleeding }\end{array}$ & Hemangiopericytoma & Ileal & Vascular tumor & Surgery \\
\hline $7, F, 64$ & $\begin{array}{l}\text { Iron-deficiency } \\
\text { anemia }\end{array}$ & GIST tumor, c-kit + & Jejunum & $\begin{array}{l}\text { Ulceration, } \\
\text { bleeding }\end{array}$ & Surgery \\
\hline $8, F, 66$ & $\begin{array}{l}\text { Unidentified } \\
\text { intestinal bleeding }\end{array}$ & GIST tumor, c-kit + & Jejunum & $\begin{array}{l}\text { Irregular erosive } \\
\text { bleeding lesion }\end{array}$ & Surgery \\
\hline 9, M, 57 & $\begin{array}{l}\text { Iron-deficiency } \\
\text { anemia }\end{array}$ & Adenocarcinoma & Jejunum & Bleeding ulcer & $\begin{array}{l}\text { Surgery and } \\
\text { chemotherapy }\end{array}$ \\
\hline $10, F, 57$ & $\begin{array}{l}\text { Malabsorption } \\
\text { Protein-losing } \\
\text { enteropathy }\end{array}$ & Diffuse T-cell lymphoma & Jejunoileal & $\begin{array}{l}\text { Ulcers and } \\
\text { erosions }\end{array}$ & $\begin{array}{l}\text { Surgical biopsy, } \\
\text { chemotherapy }\end{array}$ \\
\hline $11, \mathrm{~F}, 74$ & $\begin{array}{l}\text { Iron-deficiency } \\
\text { anemia }\end{array}$ & Adenocarcinoma & Ileal & $\begin{array}{l}\text { Nodular lesion } \\
\text { with irregular } \\
\text { surface }\end{array}$ & Surgery \\
\hline
\end{tabular}


Figure 1. Large deep ulcer in the jejunum, surrounded by cracked mucosa. A biopsy obtained by push enteroscopy showed an intestinal T-cell lymphoma.

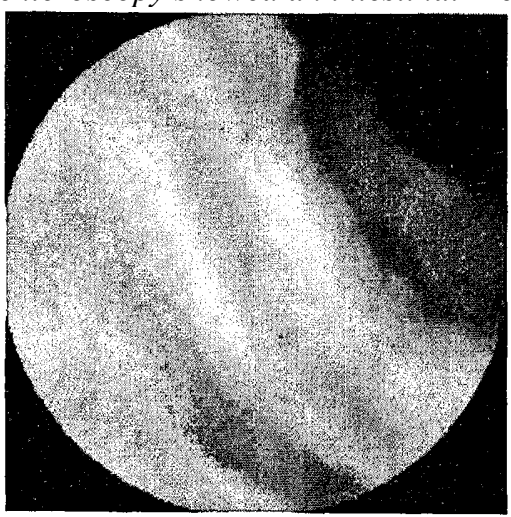

These patients had undergone a mean of 3.6 gastrointestinal diagnostic procedures before capsule endoscopy was performed. Some of these procedures had been done several times, and comprised:

esophagogastroduodenoscopy, $\mathrm{n}=13$; colonoscopy, $\mathrm{n}=11$; small-bowel radiography, $\mathrm{n}=8$; CT scan, $\mathrm{n}=4$; and push enteroscopy, $\mathrm{n}=4$.

The tumors were located in the jejunum in five patients, in the ileum in two patients, or were diffuse/multifocal (in four patients).

The endoscopic appearances of the lesions on capsule endoscopy were of erosive or ulcerative lesions in six patients, and of a tumoral lesion in five. In five cases, active bleeding was detected. A stenosing mass was present in one patient, but there were no problems in passage of the capsule.

There were, in total, four adenocarcinomas, three T-cell lymphomas, two gastrointestinal stromal (GIST) tumors, one case of multiple carcinoid tumors, and one hemangiopericytoma.

Table 2 shows the impact of capsule endoscopy on diagnosis and therapy in these 11 patients. In 10/11 patients, capsule endoscopy was considered to have had an influence on the diagnosis. In three of these ten patients, however, capsule endoscopy confirmed lesions already detected by other diagnostic procedures (patients 5, 6, and 10), so that capsule endoscopy findings had an actual impact on diagnosis in $7 / 11$ patients $(64 \%)$. The diagnostic yield after performing a classical work-up in the entire studied population (443 procedures) is therefore $1.6 \%$. In $6 / 11$ patients (55\%), capsule endoscopy had an impact on therapy.

Table 2. Influence of capsule endoscopy on diagnosis and therapy ( + some influence; - no influence)

\begin{tabular}{|c|c|c|}
\hline Patient no. & Influence on diagnosis & Influence on therapy \\
\hline 1 & $(+)$ & $(+)$ \\
\hline 2 & (-)The lesions had already been identified on a small-bowel series & $(-)$ \\
\hline 3 & $(+)$ & $(+)$ \\
\hline 4 & $\begin{array}{l}(+) \text { Lymph nodes were detected by CT scan, capsule endoscopy pointed } \\
\text { towards the diagnosis of intestinal lymphoma, but the diagnosis was } \\
\text { established by lymph node biopsy }\end{array}$ & $(-)$ \\
\hline 5 & $\begin{array}{l}(+) \text { Allowed definition of the extent of lesions detected by push- } \\
\text { enteroscopy }\end{array}$ & $(-)$ \\
\hline 6 & $(+)$ Identified the intraluminal presence of a tumor detected by CT scan & $(-)$ \\
\hline 7 & $(+)$ & $(+)$ \\
\hline 8 & $\begin{array}{l}(+) \text { Tumor was also be detected by CTscan performed after capsule } \\
\text { endoscopy }\end{array}$ & $(+)$ \\
\hline 9 & $(+)$ & $(+)$ \\
\hline 10 & $\begin{array}{l}(+) \text { Allowed definition of the extent of a process identified by push- } \\
\text { enteroscopy }\end{array}$ & $(-)$ \\
\hline 11 & $(+)$ & $(+)$ \\
\hline
\end{tabular}




\section{Discussion}

Evaluation of small-bowel disease by conventional endoscopy remains difficult. Push-enteroscopy allows visualization of $60-120 \mathrm{~cm}$ of the ligament of Treitz [3]. Routine retrograde ileoscopy is not always easy to perform and is limited to $10-60 \mathrm{~cm}$ of terminal ileum [7]. Small-bowel radiographs are able to provide correct images of this organ, but do not detect vascular abnormalities. Moreover, the best technique is enteroclysis [8], which is quite uncomfortable for the patient, is time-consuming, and has to be performed by skilled radiologists. $\mathrm{CT}$ and magnetic resonance imaging (MRI) enteroclysis are not widely available.

Capsule endoscopy is an attractive technique developed by Given Imaging and has been available for clinical purposes for about 3 years. The increasing number of publications on capsule endoscopy underlines the interest of gastroenterologists in this comfortable, safe, and efficient technology. Bleedings of undefined origin, as well as Crohn's disease, are probably the main field of application of capsule endoscopy. On the other hand, data concerning the role of capsule endoscopy in detecting small-bowel tumors, and especially malignant ones, are scarce. De Mascarenhas-Saraiva et al. recently published a small series [9]. De Franchis et al. made an important review of small-bowel malignancy by collecting abstracts and studies mentioning small-bowel malignancy as found by capsule endoscopy [10]. The percentage of small-bowel tumors in the 892 patients recorded was $3.8 \%$. In a recent published abstract, Schwartz \& Barkin recorded 49 malignant tumors found using capsule endoscopy [11]. Some of these findings, however, were located in endoscopically accessible parts of the digestive tract, so that the added diagnostic yield of capsule endoscopy is difficult to evaluate from the abstract.

A large meta-analysis was presented at the Third International Conference on capsule endoscopy in Miami, Florida, USA (B.Lewis). In this study, 9\% of occult gastrointestinal bleedings were due to small-bowel tumors. We have no clear explanation for the differences observed in the various studies $(2.5 \%$ in our study, $3.8 \%$ in the series of De Franchis et al., and 9\% in the study of Lewis). The retrospective design of the studies, the fact that Lewis considers only patients with occult bleeding, and the variable place of capsule endoscopy in local algorithms could influence the results.

In this Belgian multicenter study, we exclusively took small-bowel malignancies into account, because most findings of polyps or nodules (we found lesions described as polyps in seven patients and lesions described as nodules in three) were considered to be incidental and to have no impact on therapy. However, we cannot exclude that some of these lesions, while considered to be asymptomatic, could be small carcinoids or GIST tumors, or lymphomas. There are no data available in the literature on this point, and we need more information on the follow-up of these lesions in large studies.

We found that the diagnostic yield of capsule endoscopy after a classical work-up had been performed was $1.6 \%$. This percentage is low, but the disease is very uncommon. The mean number of diagnostic procedures performed before capsule endoscopy was 3.6, including some repeated procedures. This number of procedures done before capsule endoscopy is interestingly small, because in Belgium there is no reimbursement for capsule endoscopy, which is much more expensive than endoscopic or radiological procedures. In these circumstances, one could indeed expect that classical work-up before capsule endoscopy, especially in cases of bleeding of iron-deficiency anemia, would systematically include esophagogastroduodenoscopy, push enteroscopy, ileocolonoscopy, CT scan, and small-bowel radiography. In our series, only four push enteroscopies and four CT scans were performed before capsule endoscopy. In one case, a CT scan could afterwards identify the lesion found by capsule endoscopy. In patient 1 , the tumor was located at the proximal jejunum and could probably have been detected by push enteroscopy.

There is certainly a need to establish an algorithm for the diagnosis of small-bowel malignancies. Moreover, this algorithm will be influenced by local circumstances, such as the costs inherent to endoscopies and radiology procedures, and also whether or not capsule endoscopy is reimbursed. The most frequent clinical presentation of small-bowel tumors discovered by capsule endoscopy in this study and others was bleeding of undefined origin and iron-deficiency anemia. In accordance with other authors [12,13], and because of the diagnostic and therapeutic impact of capsule endoscopy in tumors, we could recommend the performance of capsule endoscopy after a classical endoscopic work-up (esophagogastroduodenoscopy, push enteroscopy if available, and ileocolonoscopy).

Interestingly, 36\% (4/11) of our patients presented other symptoms. The place of capsule endoscopy, especially for the indication of protein-losing enteropathy, needs further study. In any case, small-bowel malignancy is infrequent, accounting only for $2.5 \%$ of findings from a total of 443 capsule endoscopy procedures. Larger prospective studies are still needed to better define the rule and the timing of capsule endoscopy in small-bowel 
diseases, especially malignant processes.

\section{In Brief}

A retrospective case collection of 11 small-bowel malignancies revealed in 443 capsule endoscopies. The four patients with adenocarcinoma all underwent capsule endoscopy because of iron deficiency anemia, the patients with other neoplasms (lymphomas, GIST, etc.) had various indications.

\section{Competing interests}

None

\section{References}

${ }^{1}$ Ell C, Remke S, May A et al. The first prospective controlled trial comparing wireless capsule endoscopy with push enteroscopy in chronic gastrointestinal bleeding. Endoscopy 2002; 34: 685-689

${ }^{2}$ Eliakim R. Wireless capsule video endoscopy: three years of experience. World J Gastroenterol 2004; 10: 1238-1239

${ }^{3}$ Costamagna G, Shah SK, Ricciomi ME et al. A prospective trial comparing small bowel radiographs and video capsule endoscopy for suspected small bowel disease. Gastroenterology 2002; 123: 999-1005

${ }^{4}$ Eliakim R, Fischer D, Suissa A et al. Wireless capsule video endoscopy is a superior diagnostic tool compared to barium follow through and CT in patients with suspected Crohn's disease. Eur J Gastroenterol Hepatol 2003; 15: 363-367

${ }^{5}$ Maieron A, Hubner D, Blaha B et al. Multicenter retrospective evaluation of capsule endoscopy in clinical routine. Endoscopy 2004; 36 : 864-868

${ }^{6}$ Madisch A, Schimming W, Kinzel F et al. Locally advanced adenocarcinoma missed primarily by capsule endoscopy but diagnosed by push enteroscopy. Endoscopy 2003; 35: 861-864

${ }^{7}$ Landi B, Cellier C, Gaudric M et al. Long-term outcome of patients with gastro-intestinal bleeding of obscure origin explored by push enteroscopy. Endoscopy 2002; 34: 355-359

${ }^{8}$ Maglinte DD, Kelvin FM, O'Connor K et al. Current status of small-bowel radiography. Abdom Imaging 1996; 21: 247-257

${ }^{9}$ de Mascarenhas-Saraiva MN, da Silva Araujo Lopes LM. Small-bowel tumors diagnosed by wireless capsule endoscopy: report of five cases. Endoscopy 2003; 35: $865-868$

${ }^{10}$ De Franchis R, Rondonotti E. Abbiati C et al. Small-bowel malignancy. Gastrointest Endoscop Clin N Am 2004; 14: 139-148

${ }^{11}$ Schwartz GD, Barkin JS. Small bowel tumors detected by $\mathrm{M}_{2} \mathrm{~A}^{\circledR}$ capsule endoscopy. Am J Gastroenterol 2004 ; 99 Suppl: A191

${ }^{12}$ Delvaux M, Fassler I, Gay G. Clinical usefulness of the endoscopic video capsule as the initial intestinal investigation in patients with obscure digestive bleeding: validation of a diagnostic strategy based on the patient outcome after 2 months. Endoscopy 2004; 36: 1067-1073

${ }^{13}$ Pennazio M, Santucci R, Rondonotti E et al. Outcome of patients with obscure gastrointestinal bleeding after capsule endoscopy: report of 100 consecutive cases. Gastroenterology 2004; 126: 643-653 